\title{
DINÂMICA DA Ilex paraguaniensis EM DOIS FRAGMENTOS DE FLORESTA OMBRÓFILA DENSA EM MINAS GERAIS
}

\author{
Ilex paraguaniensis DYNAMICS IN TWO DENSE OMBROPHYLOUS FOREST FRAGMENTS \\ IN MINAS GERAIS
}

\author{
Lorena Oliveira Barbosa ${ }^{1}$, Ximena Mendes de Oliveira ${ }^{2}$, Luciane Naimeke Schmidt ${ }^{3}$, \\ Anny Francielly Ataide Gonçalves ${ }^{4}$, Henrique Faria de Oliveira ${ }^{5}$, José Roberto Soares Scolforo ${ }^{6}$ \\ 1,2,3,4,5,6 Universidade Federal de Lavras, Lavras, Minas Gerais, Brasil - lorena.obarbosa@gmail.com, \\ ximena_mendes@hotmail.com, lunaimekeschmidt@gmail.com,annyfrancielly@gmail.com, \\ henriqueengflorestal@yahoo.com.br\&jscolforo@dcf.ufla.br
}

\section{RESUMO}

A espécie llex paraguaniensis (erva-mate) representa importante papel na cultura e economia da região sul do Brasil, mas ainda é pouco explorada em outras regiões de ocorrência no país. O objetivo desse estudo foi avaliar a fitossociologia e dinâmica da llex paraguaniensis em fragmentos nativos localizados em Minas Gerais, uma vez que estas informações podem contribuir com um plano de manejo e conservação da espécie neste estado. Foram utilizados dados de parcelas medidas nos anos de 2005 e 2010, pertencentes a dois fragmentos nativos de Floresta Ombrófila Densa. Em 2005 foram mensurados os diâmetros das árvores que atendessem ao critério de inclusão (diâmetro à altura do peito $\geq 5 \mathrm{~cm}$ ). Em 2010, além da remedição das árvores sobreviventes, recrutamento e mortalidade também foram considerados. Com estas informações, foram calculadas as taxas de mortalidade, recrutamento, perda de área basal, ganho de área basal e rotatividade média. Os resultados mostram que número de indivíduos por hectare não foi alterado entre os períodos e que a taxa de ganho em área basal foi superior à de perda. Portanto, pôde-se concluir que a espécie se encontra estável nos fragmentos analisados e que a viabilidade de um plano de manejo para a mesma pode ser analisado.

PALAVRAS-CHAVE: Erva-mate, Fitossociologia, Manejo de floresta nativa.

\begin{abstract}
The species llex paraguariensis is important for the economics and culture at the south of Brazil, however, it is not plenty explored at other places of the country. The goal of this study is to assess phytosociology and dynamic on Ilex paraguariensis stands of a native population in Minas Gerais. This information is important for management plans and for the species conservation in this state. Data used was from plots measured in 2005 and 2010, belonging to two native stands in a dense ombrophylous forest. In 2005, trees which diameter was bigger than $5 \mathrm{~cm}$ were measured at each plot. In 2010, trees were re-measured, and recruitment and mortality were assessed as well. Mortality and recruitment ratio, basal area loss and gain and turnover were calculated as well. The number of individuals didn't change in this period and basal balance was positive in comparison with the previous assessment. We conclude that the species population is steady and that the viability for a management plan for the species need to be assessed.
\end{abstract}

KEYWORDS: Erva-mate, Phytosociology, Native forest management. 


\section{INTRODUÇÃO}

A erva-mate (Ilex paraguariensis A.St.-Hil.) é uma espécie nativa da América do Sul, abrangendo o Brasil, o Paraguai e a Argentina. No Brasil ocorre nos estados do Paraná, Rio Grande do Sul, Santa Catarina, São Paulo, Mato Grosso do Sul e em pequenas áreas de Minas Gerais e Rio de Janeiro. Pertencente à família Aquifoliaceae, a ervamate é uma espécie clímax e ciófita, ou seja, desenvolve bem na sombra em qualquer estágio da vida (SOUZA \& LORENZI, 2012; MURAKAMI et al., 2013).

Muito antes da chegada dos espanhóis e portugueses, os indígenas já utilizavam as folhas da erva-mate. Durante o século $X I X$ e início do século $X X$ a erva-mate se transformou em um dos principais produtos das exportações brasileiras, e atualmente a espécie é explorada economicamente em milhares de propriedades rurais (MARQUES et al., 2012). Com isso, ressalta-se a importância sócio econômica da espécie, sendo utilizada principalmente na produção de bebidas como chimarrão e chá, e também com grande potencial para outras aplicações na indústria (MACCARI JR \& MAZUCHOWSKI, 2000).

$\mathrm{Na}$ literatura existem diversas pesquisas sobre a Ilex paraguariensis em ervais nativos e plantados na a região sul do país. No entanto, em outras áreas, como no estado de Minas Gerais, onde foram identificadas algumas manchas de ocorrência, de acordo com o mapeamento realizado pelo projeto Inventário Florestal (SCOLFORO et al., 2008), pouco se tem estudado. De acordo com Amaral (2016) existe um grande potencial de expansão da espécie nesses locais, especialmente para as regiões altas e frias da Serra da Mantiqueira, como estratégias de conservação e recuperação da erva-mate na Mata Atlântica.

França \& Stehmann (2004) estudando a composição florística e estrutura fitossociológica de uma floresta ombrófila densa altomontana na Serra da Mantiqueira, no município de Camanducaia-MG, verificaram que as espécies do gênero llex se destacaram por serem fortemente relacionadas a altitudes elevadas, sendo que a ocorrência da erva-mate se dá frequentemente no segundo estrato, em que a altura média das árvores foi de 11 metros. Esses resultados corroboram com os de Meireles et al. $(2008,2014)$ em estudos semelhantes para a mesma região, os quais constataram que as espécies do gênero llex apresentaram maior riqueza e são consideradas muito importantes na composição florística de florestas altomontanas.

Diante da importância ecológica, social e econômica da Ilex paraguariensis (erva-mate), o presente estudo tem como objetivo avaliar a fitossociologia e dinâmica desta espécie em dois fragmentos de Floresta Ombrófila Densa Altomontana, ainda pouco estudados no estado de Minas Gerais. As informações geradas visam contribuir com a conservação e manejo da espécie na região.

\section{MATERIAL E MÉTODOS}

O estudo foi desenvolvido em dois fragmentos florestais em áreas classificadas como Floresta Ombrófila Densa Altomontana localizados no município de Camanducaia (Fragmento 1) e Lima Duarte (Fragmento 2), sul de Minas Gerais (Figura 1), sob as coordenadas geográficas -43,885 Longitude Oeste e -21,710 Latitude Sul, $-43,884$ Longitude Oeste e $-21,709$ Latitude Sul, respectivamente. O Fragmento 1 tem 181,83 hectares e o Fragmento 2 possui 102,69 hectares.

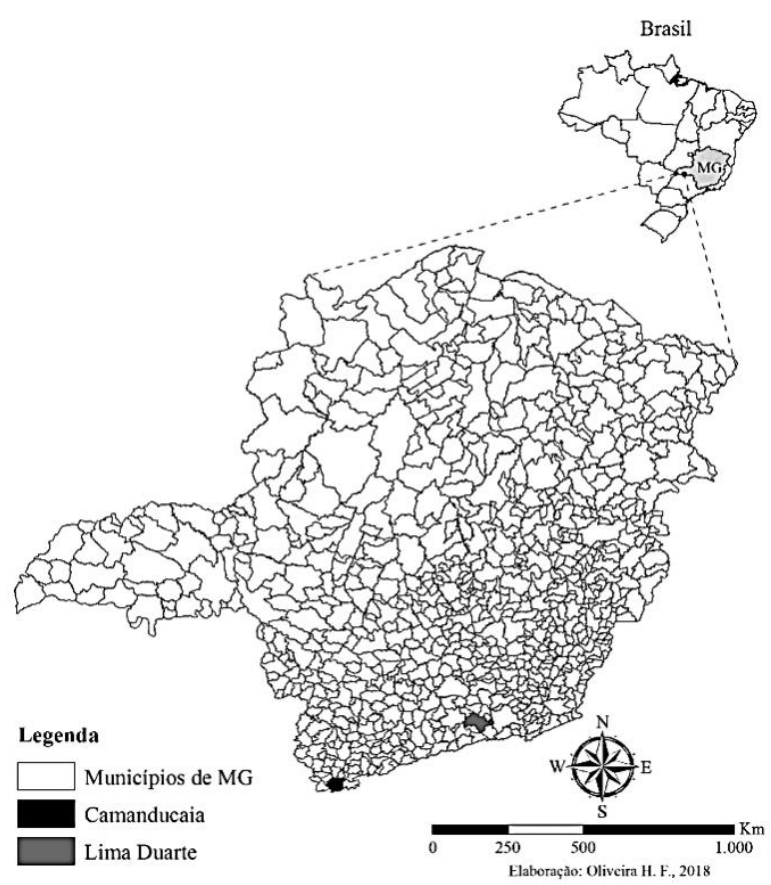

Figura 1. Localização das áreas de estudo nos municípios de Camanducaia e Lima Duarte, Minas Gerais, Brasil.

Predomina na região os solos classificados como Latossolo. O clima é do tipo superúmido, com precipitação média de $1.808,44 \mathrm{~mm}$ e temperatura média de $14,40^{\circ} \mathrm{C}$ para o Fragmento 1. Em relação ao Fragmento 2, o clima é do tipo úmido, com precipitação média variando entre 1.534 a $1.647 \mathrm{~mm}$ e temperatura média de $16,92^{\circ} \mathrm{C}$ (SCOLFORO et al., 2008).

Para a desenvolvimento do inventário florestal foi utilizado a técnica de amostragem de parcelas com área fixa (MUELLER-DOMBOIS \& ELLEMBERG, 1974), lançadas 
sistematicamente dentro dos fragmentos florestais em estudo. Foram alocadas 20 unidades amostrais no Fragmento 1 e 23 no Fragmento 2, todas de $10 \mathrm{~m} \times 100 \mathrm{~m}$ $\left(1.000 \mathrm{~m}^{2}\right)$, perfazendo área total amostrada de 2 ha e 2,3 ha, respectivamente no ano de 2005. Indivíduos arbóreos de llex paraguariensis que atendessem ao critério de inclusão (diâmetro à altura do peito (DAP) $\geq 5 \mathrm{~cm}$ ), foram amostrados com uso da fita métrica, e tiveram a altura mensurada com o uso da vara telescópica, além de terem sido identificados. No caso de perfilhamentos, mediram-se todos os ramos desde que tivessem atingido o critério de inclusão.

$\mathrm{Na}$ amostragem posterior, no ano de 2010, foi seguida a mesma metodologia, levando em consideração os sobreviventes que foram medidos novamente e, incorporando a medição de novos indivíduos, que atingiram ao critério de inclusão. Indivíduos mortos também foram registrados.

Foi realizado o cálculo da área basal (Equação 1) conforme Soares et al. (2011):

$$
A B=\sum_{i=1}^{n} g_{i}=\sum_{i=1}^{n} \frac{\pi D A P^{2}}{40000}
$$

Em que: $A B$ = área basal; gi = área seccional à altura do peito (1,3 $\mathrm{m}$ do solo); e DAP = diâmetro medido a $1,3 \mathrm{~m}$ do solo.

Para a análise da estrutura horizontal dos fragmentados amostrados, foram calculados para a espécie llex paraguariensis os parâmetros fitossociológicos tradicionais absolutos: densidade, dominância, frequência, valor de cobertura e valor de importância (DAUBENMIRE, 1968; MUELLER-DOMBOIS \& ELLENBERG, 1974). Os parâmetros fitossociológicos foram calculados por meio do Microsoft Excel ${ }^{\circledR}$.

Em seguida, para cada um dos fragmentos nas diferentes datas de medições, as árvores da espécie Ilex paraguariensis foram estratificadas em classes diamétricas, com amplitudes crescentes, como proposto por (OLIVEIRA et al., 2018).

Para realizar a análise da distribuição da frequência foi feito a análise de regressão utilizando o software $R$ ( $R$ Core Team 2018), em que o valor central das classes de diâmetro foi a variável independente do modelo e o número de indivíduos pertencentes a cada classe foi a variável dependente. Esse tipo de processamento de dados é desenvolvido para que o coeficiente angular ou a inclinação da equação de regressão possa ser obtido, e utilizado como indicativo da estrutura da população (AVILA et al., 2016; MWAVU \& WITKOWSKI, 2009).
Para o período entre 2005 e 2010 foram calculadas as taxas de mortalidade $(M)$, recrutamento $(R)$, com base no número de indivíduos, a taxa de perda $(P)$ e a taxa de ganho (G) da área basal, expressos em porcentagem, de acordo com a metodologia proposta por Sheil et al. (1995) e Sheil \& May (1996):

$$
\begin{gathered}
M=\left[1-\left(\left(N_{0}-N_{m}\right) / N_{0}\right)^{\frac{1}{t}}\right] \times 100 \\
R=\left[1-\left(1-N_{r} / N_{t}\right)^{\frac{1}{t}}\right] x 100 \\
P=\left\{1-\left[\left(A B_{0}-\left(g_{m}+g\right)\right) / g_{0}\right]^{\frac{1}{t}}\right\} x 100 \\
G=\left\{1-\left[1-\left(g_{r}+g_{g}\right) / g_{t}\right]^{\frac{1}{t}}\right\} x 100
\end{gathered}
$$

Em que: $t$ = tempo (anos) entre os inventários; $\mathrm{N}_{0}=$ número de árvores inicial; $\mathrm{N}_{\mathrm{m}}=$ número de árvores mortas; $\mathrm{N}_{\mathrm{r}}$ = número de recrutas; $\mathrm{N}_{\mathrm{t}}=$ número final de árvores (em $\mathrm{t})$; $g_{0}, g_{\mathrm{m}}, g_{\mathrm{r}}$ e $g_{\mathrm{t}}=$ área basal inicial, das árvores mortas, das árvores recrutas, e final, respectivamente; e $g_{d}$ e $g_{g}=$ decremento (perdas de fuste e redução diamétrica) e o incremento em área basal das árvores sobreviventes, respectivamente.

Conforme proposto por Korning \& Balslev (1994) e Oliveira Filho et al. (1997) a taxa média de rotatividade (Tn) foi calcula por meio da média das taxas de mortalidade e de recrutamento (Equação 6). Costa et al. (2010) citam que essa taxa é referente a dinâmica global das populações.

$$
\operatorname{Tn}=\frac{R+M}{2}
$$

\section{RESULTADOS E DISCUSSÃO}

No Fragmento 1 (Camanducaia) foram amostradas 49 árvores de llex paraguariensis em 2005 e 52 no ano de 2010. Entretanto no Fragmento 2 (Lima Duarte) foram amostradas 11 árvores nos dois anos de inventário, ou seja, não houve aumento no número de árvores amostradas no período de cinco anos para este fragmento.

Marcon et al. (2014), estudando a similaridade florística das florestas supermontanas no domínio atlântico, verificaram que, embora não tenha sido observada a presença de Araucaria angustifolia (Bertol.) Kuntze nos remanescentes de Minas Gerais (Camanducaia), foram encontradas espécies características da Floresta Ombrófila Mista (FOM), como a llex paraguariensis, indicando esta 
área como transicional e justificando sua maior similaridade com as áreas de FOM.

A distribuição de frequência das árvores por agrupamento em classes de diâmetro do Fragmento 1 e 2 estão exibidas, respectivamente, na Figura $2 \mathrm{a}$ e $2 \mathrm{~b}$. Em ambos os fragmentos a distribuição diamétrica apresentou uma aproximação à curva exponencial negativa (Jinvertido) nos dois anos de medições, com maior concentração de árvores nas classes iniciais. Longhi (2016) destaca que esse tipo de comportamento da distribuição é característico de florestas multiespecíficas e multiâneas, além de ser um indicativo de fitofisionomias autorregenerativas.
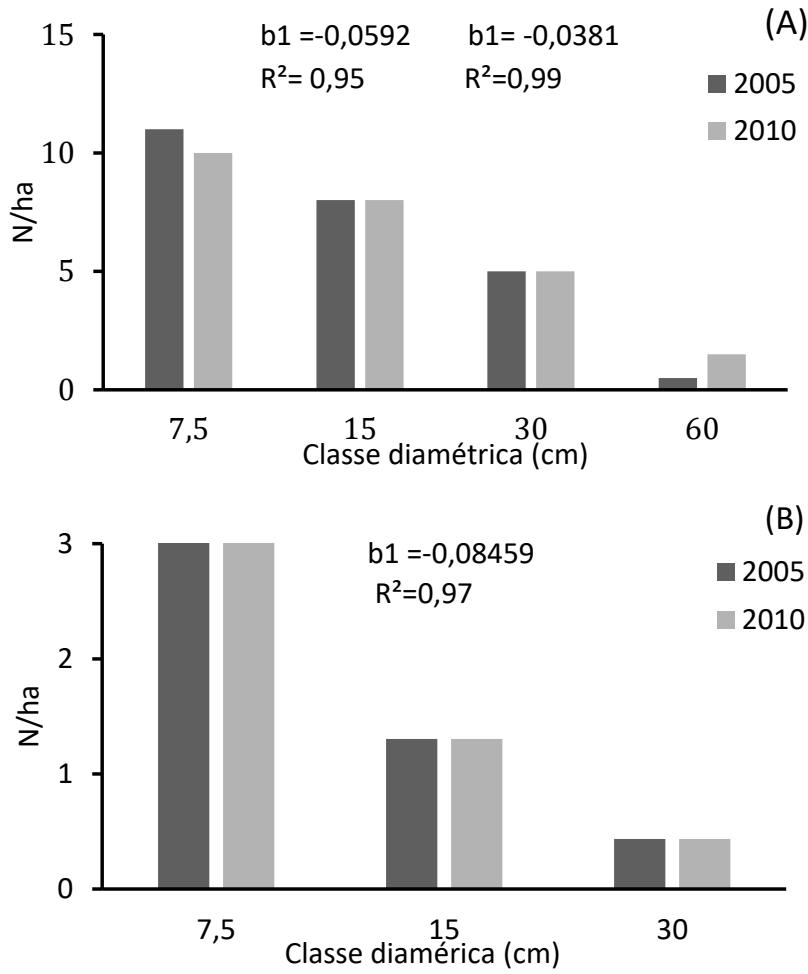

Figura 2. Distribuição diamétrica da população Ilex paraguariensis nos fragmentos 1 (A) e 2 (B) de uma Floresta Ombrófila Montana.

O padrão de curva J-invertido é comum em florestas nativas, mas quando se estuda populações individuais algumas espécies podem não apresentar o mesmo padrão. Esse fato ocorre devido a autoecologia das espécies e por falhas no processo de regeneração das populações que variam de acordo com as condições ambientais e o histórico de perturbação de cada área (AVILA et al. 2016).

A análise das distribuições por meio do ajuste de equações nos anos de medições, indicou coeficientes de inclinação negativos e bons ajuste com $\mathrm{R}^{2}$ acima de $90 \%$. Os valores de b1 são pequenos e de acordo com Avila et al. (2016) quanto menor valor da inclinação na função de
Meyer maior o indicativo da população apresenta-se autorregenerativa.

Outra observação sobre a distribuição diamétrica, de acordo com Schaaf et al. (2006) é que nem sempre o comportamento em exponencial negativa vai indicar a permanência de uma espécie na estrutura futura da floresta, todavia, se uma espécie tem poucos indivíduos nas classes inferiores, mas pequena probabilidade de morrer devido à competição, é bem provável que tal espécie se mantenha na floresta. No entanto, uma espécie na qual grande parte dos indivíduos esteja sujeita a morrer devido à competição, necessita de uma grande frequência nas classes diamétricas inferiores para ter chances de sobreviver na comunidade.

A área basal da área total do Fragmento 1 aumentou de 31,9 para $33,9 \mathrm{~m}^{2} \mathrm{ha}^{-1}(5,8 \%)$, entretanto no Fragmento 2 observou-se uma redução pequena de 0,67\%, 37,8 para $37,6 \mathrm{~m}^{2} \mathrm{ha}^{-1}$, entre os anos de medições. O aumento e a redução podem ser justificados pela variação no número de árvores amostradas, pela porcentagem de mortalidade e recrutamento.

A área basal da população de $I$. paraguariensis aumentou no Fragmento 1 (Figura 3a) de 0,56 para 0,62 $\mathrm{m}^{2} \mathrm{ha}^{-1}(9,6 \%)$ e no Fragmento 2 (Figura 3b) 7,2\%, registrando 0,56 para $0,60 \mathrm{~m}^{2} \mathrm{ha}^{-1}$.
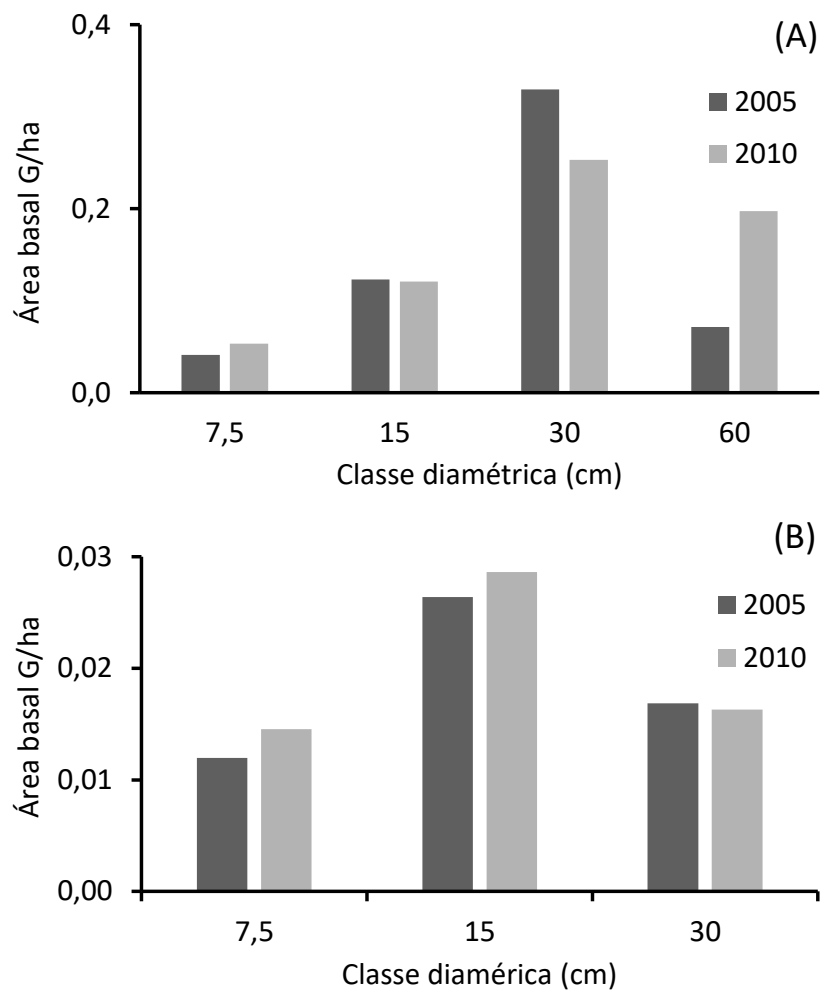

Figura 3. Distribuição da área basal por hectare em classe diamétrica da população de Ilex paraguariensis nos fragmentos $1(\mathrm{~A})$ e 2 (B) de Floresta Ombrófila Montana. 
Os parâmetros fitossociológicos densidade absoluta (N/ha) e dominância absoluta (G/ha) aumentaram, respectivamente, 5,8\% e 97,5\% no Fragmento 1 no período de 2005 a 2010. No Fragmento 2 como não houve aumento no número de árvores observadas o parâmetro densidade absoluta permaneceu com 4,78 N/ha, mas observou-se o aumento 7,18\% na dominância absoluta (G/ha).

Os parâmetros relativos não devem ser comparados uma vez que consideram toda a população, se baseiam também nos parâmetros das outras espécies.

Os valores das taxas de dinâmica da população arbórea estão apresentados na Tabela 1. No Fragmento 1, observou-se que a taxa de recrutamento $\left(1,26 \%\right.$.ano $\left.{ }^{-1}\right)$ foi igual a de mortalidade, o que acarretou em um mesmo número de árvores/ha. Contudo no Fragmento 2 não foram identificados mortalidade e recrutamento, uma vez que não houve diferença no número de árvores amostradas entre os anos de medições.

Tabela 1. Dinâmica da população de Ilex paraguariensis em dois fragmentos de floresta Ombrófila Montana, Minas Gerais, no período de 2005 a 2010.

\begin{tabular}{|c|c|c|}
\hline Densidade & Frag. 1 & Frag. 2 \\
\hline Número de árvores.ha-1 (2005) & 24,5 & 4,8 \\
\hline Número de árvores.ha-1 (2010) & 24,5 & 4,8 \\
\hline Número de árvores mortas & 3 & 0 \\
\hline Número de árvores recrutadas & 3 & 0 \\
\hline Taxa de mortalidade $\left(\%\right.$ ano $\left.{ }^{-1}\right)$ & $1,26 \%$ & 0 \\
\hline Taxa de recrutamento $\left(\%\right.$ ano $\left.{ }^{-1}\right)$ & $1,26 \%$ & 0 \\
\hline Rotatividade (\%) & $1,26 \%$ & 0 \\
\hline Área basal em $2005\left(\mathrm{~m}^{2}\right)$ & 1,13 & 0,13 \\
\hline Área basal em $2010\left(\mathrm{~m}^{2}\right)$ & 1,25 & 0,14 \\
\hline Área basal das árvores mortas $\left(\mathrm{m}^{2}\right)$ & 0,11 & 0 \\
\hline Área basal das recrutadas $\left(\mathrm{m}^{2}\right)$ & 0,01 & 0 \\
\hline Incremento das sobreviventes $\left(\mathrm{m}^{2} \mathrm{ano}^{-1}\right)$ & 0,226 & 0,025 \\
\hline Taxa de perda $\left(\%\right.$ ano $\left.{ }^{-1}\right)$ & $2,22 \%$ & $0,23 \%$ \\
\hline Taxa de ganho (\% ano $\left.{ }^{-1}\right)$ & $2,23 \%$ & $1,71 \%$ \\
\hline Rotatividade (\%) & $2,22 \%$ & $0,97 \%$ \\
\hline
\end{tabular}

O ganho e a perda em área basal foram praticamente o mesmo no Fragmento 1, entretanto o mesmo não aconteceu com o Fragmento 2, onde a perda da área basal $(0,23 \%)$ foi menor referente ao ganho $(1,71 \%)$.

As baixas taxas de mortalidade, recrutamento e rotatividade indicam que a população de Ilex paraguariensis nos dois fragmentos encontra-se em aceleração da dinâmica (KORNING; BALSLEV, 1994), caracterizada pela acumulação de área basal e o incremento periódico em área basal (IPAg) com (0,226 e $0,025 \mathrm{~m}^{2}$ ano $^{-1}$ ). Segundo Silva Neto et al. (2017) uma pequena diferença entre a mortalidade e recrutamento oscilando devido a fatores principalmente internos, mantenedores do equilíbrio dinâmico da população.

A Figura 4 mostra o comportamento do IPAg dos indivíduos de llex paraguariensis em relaçãp às classes diamétricas nos dois fragmentos. $O$ fragmento 1 apresentou IPAg de 0,23;0,33;0,23 e 0,32 $\mathrm{m}^{2}$ ano-1, $^{-1}$ respectivamente, para as classes diamétricas com valor central de 7,5; 15; 30 e 60. No fragmento 2 IPAg foi menor para todas as classes em comparação ao fragmento 1 , apresentando IPAg de 0,16; 0,19 e 0 nas classes que continham indivíduos de llex paraguariensis, respectivamente, as classes diamétricas com valor central de 7,$5 ; 15$ e 30 .

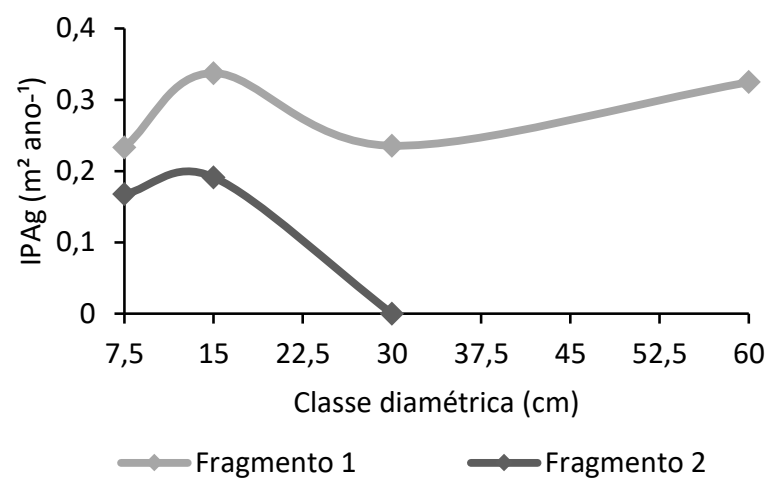

Figura 4. Incremento periódico em área seccional de llex paraguariensis em dois fragmentos de floresta Ombrófila Montana, Minas Gerais, no período de 2005 a 2010.

No estudo de Cubas et al. (2016) a espécie Ilex paraguariensis apresentou a menor taxa de crescimento no intervalo de cinco anos entre as espécies de maior IVI. Este fato foi ocasionado devido à baixa vitalidade e sanidade das plantas, afetadas pelas práticas intensivas de exploração das folhas e ramos.

\section{CONCLUSÕES}

As informações fornecidas neste estudo mostram que a espécie se manteve estável nas duas medições, com um intervalo de tempo de 5 anos. Com isto, conclui-se que a espécie se encontra em estado de conservação em ambos os fragmentos, permitindo a continuidade de estudos que analisem a viabilidade de um plano de manejo sustentável da mesma nas regiões estudadas no estado de Minas Gerais. 


\section{REFERÊNCIAS}

AMARAL, M.M. Construção de indicadores de sustentabilidade da erva-mate (Ilex paraguariensis) na Mata Atlântica. Série mercado Mata Atlântica, cadernos da reserva da biosfera da Mata Atlântica, n.47, 2016.

AVILA, A.L. de et al. Estrutura populacional e regeneração de espécies arbóreas na Floresta Nacional de São Francisco De Paula, Rio Grande do Sul. Ciência Florestal, v.26, n.3, p.825-838, 2016.

COSTA, M.P. et al. Avaliação do processo de reabilitação de um trecho de floresta ciliar na bacia do rio Itapemirim/ES. Revista Árvore, v.34, n 5, p.835-851, 2010.

CUBAS, R. et al. Incremento, ingresso, mortalidade em um remanescente de floresta ombrófila mista em Três Barras - SC. Ciência Florestal, v.26, n.3, p.889-900, 2016.

DAUBENMIRE, R. Plant communities: a textebook of plant synecology. New York: Harper \& Row, 1968.

FRANÇA, G.S.; STEHMANN, J.R. Composição florística e estrutura do componente arbóreo de uma floresta altimontana no município de Camanducaia, Minas Gerais, Brasil. Revista Brasileira de Botânica, v.27, n.1, p.19-30, 2004.

KORNING, J.; BALSLEV, H. Growth and mortality of trees in Amazonian tropical rain forest in Ecuador. Journal of Vegetation Science, v.4, n.1, p.77-86, 1994.

LONGHI, R.V. Ordenamento e condução da produção em floresta Ombrófila Mista no estado do rio grande do Sul. 2016. 148p. (Tese de doutorado).

MACCARI JR, A.; MAZUCHOWSKI, J.Z. Produtos alternativos e desenvolvimento da tecnologia industrial na cadeia produtivada erva-mate. Curitiba: Câmara setorial da cadeia produtiva da ervamate Paraná, MCT/CNPq/PROJETO PADCT Erva-mate, 2000.

MARCON, A.K. et al. Similaridade florística das florestas superomontanas no Domínio Atlântico, Brasil. Revista Árvore, v.38, n.5, p.787-797, 2014.

MARQUES, A.C. et al. Florestas nacionais e desenvolvimento de pesquisas: o manejo da Erva-Mate (Ilex paraguariensis A.St.- Hil.) na Flona de Três Barras/SC. Biodiversidade Brasileira, v.2, n.2, p.4-17, 2012.

MEIRELES, L.D. et al. Composição florística da vegetação altimontana do distrito de Monte Verde (Camanducaia, MG), Serra da Mantiqueira Meridional, Sudeste do Brasil. Rodriguésia, v.65, n.4, p.831-859, 2014.

MEIRELES, L.D. et al. Variações na composição florística e na estrutura fitossociológica de uma floresta ombrófila densa altomontana na Serra da Mantiqueira, Monte Verde, MG. Revista Brasileira Botânica, v.31, n.4, p.559-574, 2008.

MUELLER-DOMBOIS, D.; ELLEMBERG, H. Aims and methods of vegetation ecology. New York: John Wiley \& Sons. 1974.
MURAKAMI, A.N.N. et al. Concentration of biologically active compounds extracted from llex paraguariensis St. Hil. by nanofiltration. Food Chemistry, v.141, n.1, p.60-65, 2013.

MWAVU, E.N.; WITKOWSKI, T.F. Population structure and regeneration of multiple-use tree species in a semi-deciduous African tropical rainforest: Implications for primate conservation. Forest Ecology and Management, v.258, p.840-849, 2009.

OLIVEIRA FILHO, A.T. et al. Effects of past disturbance and edges on tree community structure and dynamics within a fragment of tropical semideciduous forest in south-eastern Brazil over a five years period (1987-1992). Plant Ecology, v.131, n.1, p.45-66, 1997.

OLIVEIRA, H.F. et al. Modificações florístico-estruturais em uma floresta neotropical. Ciência Florestal, v.28, n.3, p.888-897, 2018.

R Core Team 2016. R: A Language and Environment for Statistical Computing. Viena: R Foundation for Statistical Computing.

SCHAAF, L.B. et al. Alteração na estrutura diamétrica de uma floresta ombrófila mista no período entre 1979 e 2001 . Revista Árvore, v.30, n.2, p.283-295, 2006

SCOLFORO, J.R. et al. Amostragem e caracterização dos fragmentos inventariados. In: Inventário Florestal de Minas Gerais - Floresta Estacional Semidecidual e Ombrófila: Florística, Estrutura, Diversidade, Similaridade, Distribuição Diámetrica e de Altura, Volumetria, Tendências de Crescimento e Áreas Aptas para Manejo Florestal. Lavras, 2008.

SHEIL, D. et al. The interpretation and misinterpretation of mortality rate measures. Journal of Ecology, v.83, n.2, p.331-333, 1995.

SHEIL, D.; MAY, R.M. Mortality and recruitment rate evaluations in heterogeneous tropical forests. Journal of Ecology, v.84, n.1, p.91-100, 1996.

SILVA NETO et al. Dinâmica da comunidade arbórea em um fragmento de cerrado Sensu Stricto em Minas Gerais, Brasil. Scientia Forestalis, v.45, n.113, p.21-29, 2017.

SOARES, C.P.B. et al. Dendrometria e inventário florestal. 2. ed. Viçosa: UFV, 2011.

SOUZA, V.C.; LORENZI, H. Botânica Sistemática: Guia ilustrado para identificação das famílias de Fanerógamas nativas e exóticas no Brasil, baseado em APG III. 3. ed. Nova Odessa: Plantarum, 2012. 